San Jose State University

SJSU ScholarWorks

Master's Theses

Master's Theses and Graduate Research

Spring 2016

\title{
Perceived Organizational Support and Perceived Supervisor Support as Antecedents of Work Engagement
}

\author{
Kelista Lea Burns \\ San Jose State University
}

Follow this and additional works at: https://scholarworks.sjsu.edu/etd_theses

\section{Recommended Citation}

Burns, Kelista Lea, "Perceived Organizational Support and Perceived Supervisor Support as Antecedents of Work Engagement" (2016). Master's Theses. 4678.

DOI: https://doi.org/10.31979/etd.8hf7-dh9p

https://scholarworks.sjsu.edu/etd_theses/4678

This Thesis is brought to you for free and open access by the Master's Theses and Graduate Research at SJSU ScholarWorks. It has been accepted for inclusion in Master's Theses by an authorized administrator of SJSU ScholarWorks. For more information, please contact scholarworks@sjsu.edu. 


\title{
PERCEIVED ORGANIZATIONAL SUPPORT AND PERCEIVED SUPERVISOR SUPPORT AS ANTECEDENTS OF WORK ENGAGEMENT
}

\author{
A Thesis \\ Presented to \\ The Faculty of the Department of Psychology \\ San José State University \\ In Partial Fulfillment \\ of the Requirements for the Degree \\ Master of Science
}

by

Kelista Lea Burns

May 2016 
(C) 2016

Kelista Lea Burns

ALL RIGHTS RESERVED 
The Designated Thesis Committee Approves the Thesis Titled

PERCEIVED ORGANIZATIONAL SUPPORT AND PERCEIVED SUPERVISOR SUPPORT AS ANTECEDENTS OF WORK ENGAGEMENT

by

Kelista Lea Burns

APPROVED FOR THE DEPARTMENT OF PSYCHOLOGY

SAN JOSÉ STATE UNIVERSITY

May 2016
Dr. Howard Tokunaga
Department of Psychology
Dr. Megumi Hosoda
Department of Psychology
Dr. B. Lynn Ware
Integral Talent Systems, Inc. 


\title{
ABSTRACT \\ PERCEIVED ORGANIZATIONAL SUPPORT AND PERCEIVED SUPERVISOR SUPPORT AS ANTECEDENTS OF WORK ENGAGEMENT
}

\author{
by Kelista Lea Burns
}

Research has examined how providing employees with support through the organization and its supervisors is related to beneficial workplace outcomes. However, the use of nearly identical scales in measuring perceived organizational support (POS) and perceived supervisor support (PSS) might have led to consistent correlations and redundancies between the two constructs. To explore whether these scales are problematic in measuring POS and PSS, the purpose of this study was to develop and test new measures of POS and PSS designed to capture the unique characteristics of each construct. Additionally, organizations have become particularly interested in the benefits of work engagement; more specifically, POS and PSS have been found to be predictive of work engagement. Thus, the purpose of this study was also to use the proposed scales to measure POS and PSS as antecedents of work engagement. Participants in this study included 382 employees in a Southern California healthcare company. The findings of this study suggest that the proposed measures were able to successfully capture the unique qualities of POS and PSS. Furthermore, POS and PSS were found to be predictive of work engagement, with POS being the stronger predictor. These findings also suggest that while providing employees with supervisor support increases engagement, organizational support is likely to make a larger impact. However, perceptions of organizational support are likely to include how employees perceive support from their supervisors. 


\section{ACKNOWLEDGEMENTS}

I would like to thank the faculty as well as my cohort in the $\mathrm{I} / \mathrm{O}$ graduate program at SJSU for all of the countless hours spent both in and out of the classroom. Being a part of this program has been one of the most amazing experiences I have had, and I am so grateful for all of the knowledge and skills I have gained in these past two years. Thank you to all of my thesis chairs for being on my committee. I am especially grateful for Howard and Megumi, and all of their support throughout this process. You are truly inspirational people, and your dedication to your students far surpasses the requirements of your job. Howard, thank you for all of your wisdom, advice, and kind words you have provided me these past two years, and for those to come.

I also want to thank all of my family and friends who have been there for me throughout this process. You have pushed me to work harder than I thought possible, and to strive for the best. All of your support and understanding has allowed me to remain motivated throughout this long journey. Andrew, I cannot begin to express my gratitude for helping me during one of the most important moments in my life. Your love and support has made such a positive impact in my life, and I truly appreciate all of the sacrifices you have made for me. Thank you for always being patient, kind, and caring towards me, I love you so much.

I want to dedicate my thesis to my Grammie, Nana, and Papa. You have been the most positive and influential people in my life. Without your love, patience, and guidance, I am not sure this would have been possible. Thank you for everything you have ever done for me. Receiving my master's degree is truly a dream come true. 


\section{TABLE OF CONTENTS}

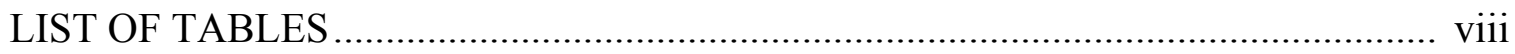

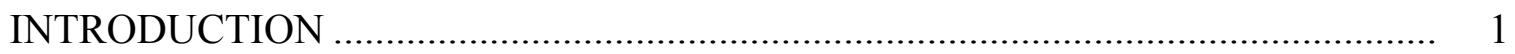

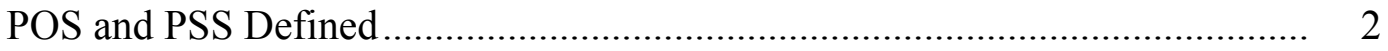

POS and PSS as Antecedents of Workplace Outcomes..................................... 5

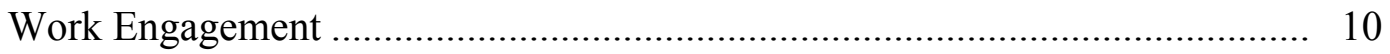

POS and PSS as Antecedents of Work Engagement ...................................... 12

The Hypothesized Relationship Between POS and PSS ................................. 14

The Measurement of POS and PSS _............................................................ 16

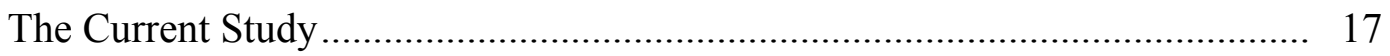

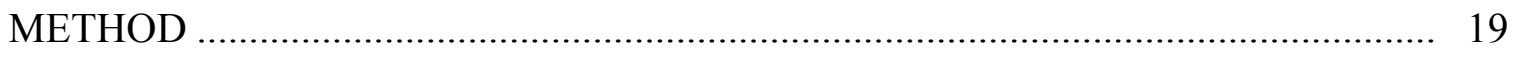

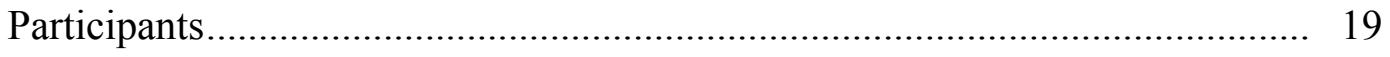

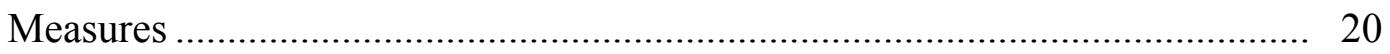

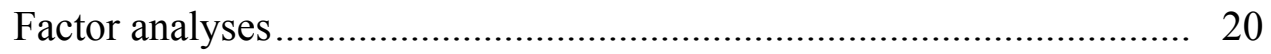

Perceived organizational support (POS) ……………........................ 25

Perceived supervisor support (PSS) .................................................... 25

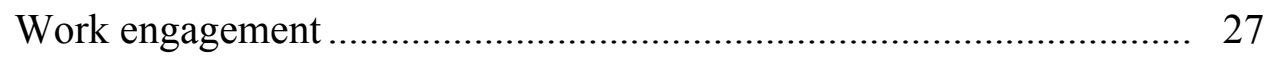

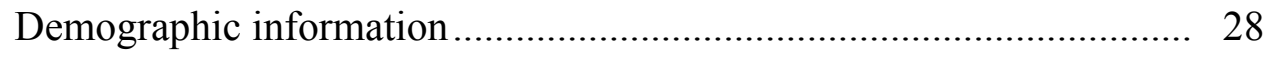

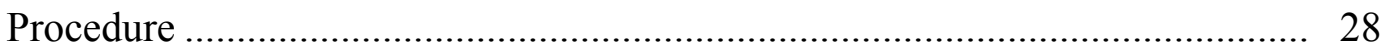

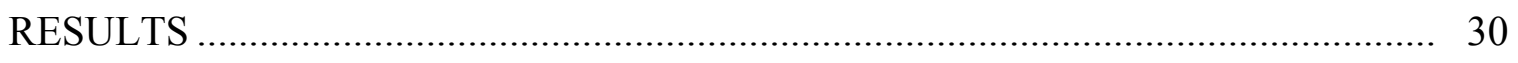

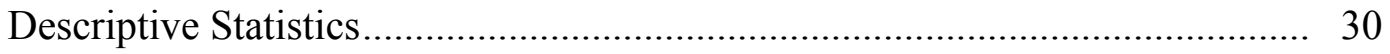

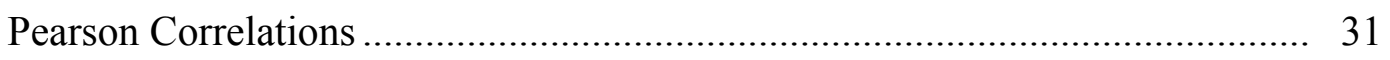


Inferential Statistics …........................................................................ 32

Standard multiple regression analysis ................................................. 32

Hierarchical multiple regression analysis ........................................... 33

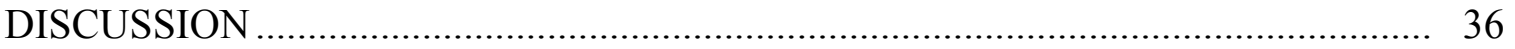

Summary of Results ........................................................................... 36

Theoretical Implications …………….................................................. 37

Practical Implications.......................................................................... 38

Strengths and Limitations of the Current Study ............................................. 39

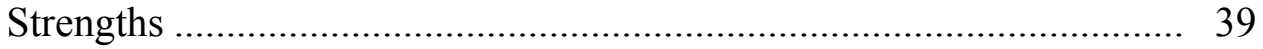

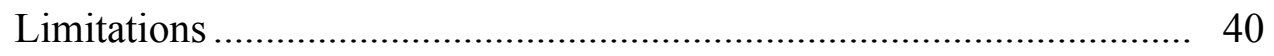

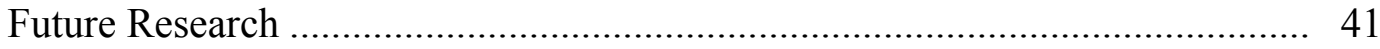

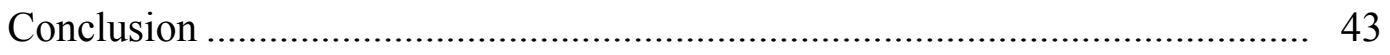

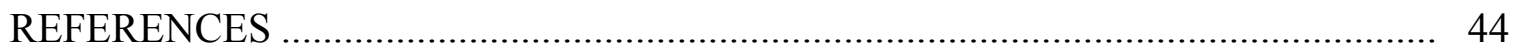




\section{LIST OF TABLES}

Table 1. Demographic Characteristics of Participants ......................................... 20

Table 2. Factor Analysis 1: POS \& PSS Scales ................................................. 21

Table 3. Factor Analysis 2: POS \& PSS Scales ................................................. 26

Table 4. Descriptive Statistics of Variables .................................................... 31

Table 5. Pearson Correlations of Variables ......................................................... 32

Table 6. Standard Multiple Regression Analysis: Predicting Work Engagement From POS and PSS ......................................................................... 33

Table 7. Hierarchical Multiple Regression Analysis: Predicting Work Engagement

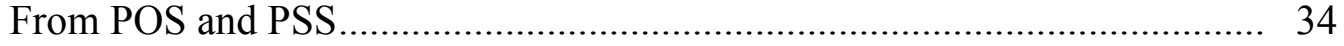




\section{Introduction}

In today's workplace, organizations are striving to find efficient methods to retain their talent in order to maintain a competitive edge. Studies have shown that various types of support in the workplace can lead to positive outcomes, such as employee retention, organizational commitment, and job performance (Baran, Shanock, \& Miller, 2012; Eisenberger, Stinglhamber, Vandenberghe, Sucharski, \& Rhoades, 2002; Masterson, Lewis, Goldman, \& Taylor, 2000; Rhoades \& Eisenberger, 2002; Rhoades, Eisenberger, \& Armeli, 2001). Two types of support have been shown to lead to positive work outcomes: perceived organizational support (POS) and perceived supervisor support (PSS; DeConinck \& Johnson, 2009; Kreiner, 2006 Pazy \& Ganzack, 2006; Lapalme, Tremblay \& Simard, 2009; Pan \& Yeh, 2012). Studies have used these constructs both independently as well as combined together to predict various work outcomes.

Consistent significant correlations have been found between POS and PSS (Campbell, Perry, Maertz, Allen, \& Griffeth, 2013; DeConinck \& Johnson, 2009; Eisenberger et al., 2002; Lapalme, Tremblay, \& Simard, 2009; Ng \& Sorensen, 2008; Saks, 2006) which have raised the question of how distinctive the two constructs are from each other and highlight potential issues in differentiating the ability of POS and PSS to predict work outcomes. Perceptions of supervisor support differ from perceptions of organizational support in that PSS is explicitly determined by the amount of care supervisors provide to their employees, how much they make employees feel valued, and the perceived concern they have in regards to their employees' well-being. POS is 
determined by more global perceptions of employees, encompassing how the organization as a whole supports its employees through recognizing their contributions and caring about their well-being. The purpose of this study was to develop and test exploratory measurements of POS and PSS designed to capture the unique characteristics of each construct.

One outcome of POS and PSS that has become a major interest to organizations is work engagement (Dabke \& Patole, 2014; Saks, 2006). It has been proposed that three types of employees exist in the workplace: those who are engaged, those who are disengaged, and those who are actively disengaged (Crabtree, 2005). The average ratio of employees that are engaged to actively disengaged has been estimated to be approximately 2 to 1 (Ran \& Prabhakar, 2011). Work engagement occurs when employees are involved with their work, are committed, and feel enthusiastic and passionate about their work (Ram \& Prabhakar, 2011). Work engagement is of particular interest to many organizations due to its benefits such as job satisfaction, organizational commitment, a reduction in intention to quit, organizational citizenship behavior (OCBs), customer satisfaction, organizational success, and greater financial return on employees, (Dabke \& Patole, 2014; Saks, 2006; Xanthopoulou, Bakker, Demerouti, \& Schaufeli, 2009). Consequently, the second purpose of the current study was to assess the ability of new measures of POS and PSS to predict work engagement.

\section{POS and PSS Defined}

POS is defined as a general belief in which employees feel that their organization values their contributions and cares about their well-being (Krishhan \& Mary, 2012; 
Rhoades and Eisenberger, 2002; Settoon, Bennett, \& Liden, 1996). POS is derived from Organizational Support Theory (Eisenberger, Huntington, Hutchison, \& Sowa, 1986). It explains relationships between employers and employees based on social exchange theory, and how employees perceive support dependent on how they personify the organization. According to the theory, employees view the organization as having humanlike characteristics and take its favorable treatment or unfavorable treatment as an indication that the organization favors or disfavors them as an individual.

POS is the beliefs of employees in regards to the extent to which the organization meets their socio-emotional needs, and how the organization responds to increased efforts at work (Eisenberger, Huntington, Hutchison, Sowa, 1986; Krishan \& Mary, 2012; Settoon, Bennet, \& Liden, 1996). A few factors are believed to influence whether employees perceive organizational support, such as organizational rewards and job conditions, and perceived fairness (Baran, Shanock, \& Miller, 2012). Organizational rewards and job conditions incorporate methods in which employees are recognized for their contributions as well as the working environment itself (Rhoades \& Eisenberger, 2002). This includes rewards and conditions such as recognition, pay, promotions, job security, job autonomy, training and development experiences, and work-family policies (Rhoades \& Eisenberger, 2002). Employees evaluate the amount of assistance and equipment provided to them by the organization to help them complete assignments, as well as being given training and development in areas that are of interest to the employee (LaMastro, 2000). Perceived fairness in relation to POS includes procedural justice, interactional justice, as well as the perception of organizational politics (Rhoades \& 
Eisenberger, 2002). Perceived organizational politics refers to the way in which employees believe the organization is attempting to influence others in ways that promote the interest of the organization, often at the expense of its employees (Rhoades \& Eisenberger, 2002). Where perceptions of procedural justice and interactional justice are likely to lead to an increase of POS, perceptions of organizational politics are more related to a reduction of POS (Rhoades \& Eisenberger, 2002).

Employees also perceive organizational support based on how they personify the company. Research has stated that employees' perceptions of organizational support will increase or decrease depending on how they attach humanlike characteristics to the organization (Eisenberger et al., 1986; Shanock \& Eisenberger, 2006). Levinson (1965) has explained these humanlike characteristics as how the organization is represented through the action of its agents, its policies, norms, and culture that provide continuity and prescribe role behaviors, and its exertion of power over employees (Rhoades \& Eisenberger, 2002; Shanock \& Eisenberger, 2006). For example, the work environment or culture of a company embodies the company in a way that employees gain an understanding of the behavior and language that are considered acceptable. This understanding portrays the company in a way that employees feel a sense of connection to it.

In addition to employees' global perceptions regarding organizational support, they also develop an overall opinion of their supervisors, known as perceived supervisor support (PSS). PSS is defined as the extent to which employees believe their supervisors value their contributions, offer assistance, and care about their well-being (Cole, Bruch, 
\& Vogel, 2006; Eisenberger et al., 2002; House, 1981; Kossek, Pichler, Bodner, \& Hammer, 2001; Kottke \& Sharafinski, 1988). Similar to how employees observe how their organization cares about and respects them, PSS involves developing perceptions of how their supervisors care for them and value their contributions. PSS is different from POS, however, in that PSS specifically focuses on how supervisors provide employees with support as agents of the organization. PSS consists of interactions between the supervisor and his or her employee that are deemed positive, which ultimately increase the level of PSS; alternatively, negative interactions have been shown to reduce PSS (Cole et al., 2006).

\section{POS and PSS as Antecedents of Workplace Outcomes}

Previous research has used POS and PSS both separately and together to predict various workplace outcomes. Studies that have measured POS as a separate construct from PSS in predicting outcomes give direct insight into the workplace attitudes and behaviors that can perhaps only be predicted by POS.

Studies have used POS alone to predict behaviors such as extra-role behaviors (OCBs; Rhoades \& Eisenberger, 2002), and withdrawal behaviors such as absenteeism, tardiness, and voluntary turnover (Rhoades \& Eisenberger, 2002). Extra-role behaviors are actions made by the employees that go above and beyond their explicitly stated job responsibilities (Rhoades \& Eisenberger, 2002). These types of activities include helping behaviors, protecting the company from risk, suggesting improvements to the company, and acquiring knowledge and skills that would be beneficial to the company (George \& Brief, 1992). The results of studies investigating POS as a predictor of extra-role 
behaviors show a positive relationship between POS and OCBs, suggesting that increased perceptions of organizational support are likely to lead to employees displaying more extra-role behaviors (Eisenberger, Johnson, Sucharski, \& Aselage, 2009; Rhoades \& Eisenberger, 2002). A meta-analysis on POS that included 20 performance studies reported that the relationship between POS and OCBs was stronger than the relationship between POS and in-role performance (Rhoades \& Eisenberger, 2002).

POS has also been used to predict withdrawal behaviors (Rhoades \& Eisenberger, 2002). Absenteeism, a type of withdrawal behavior, involves employees missing work either voluntarily or involuntarily (Eder \& Eisenberger, 2008). Studies investigating POS as a predictor of absenteeism have shown a moderately strong and negative correlation between them (Rhoades \& Eisenberger, 2002). In relation to POS, those who believe that their organization cares about them are likely to reciprocate by being attendant at work (Rhoades \& Eisenberger, 2002).

Tardiness (when employees are late to work) is an outcome of POS that tends to decrease with higher perceptions of organizational support (Eder \& Eisenberger, 2008). Studies have reported that this relationship is strong, where low POS greatly increased tardiness (Eder \& Eisenberger, 2008). This indicates that when employees believe the organization values them and their contributions, they are more likely to come to work on time.

POS has also been used as an antecedent of voluntary turnover (Rhoades \& Eisenberger, 2002). Turnover is a general term that describes an employee leaving the company, whereas voluntary turnover is when the employee chooses to leave. A 
moderately strong and negative correlation has been found between POS and voluntary turnover, where increased POS is likely to lead to a decrease in voluntary turnover (Rhoades \& Eisenberer, 2002). These results suggest that those organizations that are perceived to care about their employees' well-being are less likely to have their employees who leave their organization by choice.

POS has also been shown to be a predictor of job attitudes. One such attitude is organizational commitment, which is the level of loyalty employees feel towards their employers (Meyer \& Allen, 1991). A positive relationship has been found between POS and organizational commitment, where people reciprocate high perceived organizational support with being more committed to their organization (Rhoades \& Eisenberger, 2002).

Job-related affect such as job satisfaction and positive moods are likely to follow the perception of organizational support (Rhoades \& Eisenberger, 2002). Due to POS meeting socio-emotional needs, increasing performance-reward expectancies, and ensuring assistance when needed, POS contributes to employees' feelings of satisfaction with their job (Rhoades \& Eisenberger, 2002). POS can influence positive mood through the workplace environment, where POS increases feelings of self-efficacy and worth (Eisenberger et al., 2001; George \& Brief, 1992).

PSS has been studied independently from POS as an antecedent of workplace outcomes. In terms of work behaviors, results have shown that PSS has a positive relationship with job performance, where an increased perception of supervisor support leads to higher performance levels in employees (DeConinck \& Johnson, 2009). These 
results indicate that when supervisors are supportive of their employees, they are likely to improve job performance levels overall.

PSS has also been related to attitudes separately from POS, such as job satisfaction. In a study investigating the relationships between work environment perceptions and job satisfaction, PSS was found to be positively and significantly related to job satisfaction (Babin \& Boles, 1996). This indicates that as employees feel their supervisors are being more supportive of them, they are more likely to be satisfied with their job.

In addition to research that studied POS and PSS individually, several studies have measured both POS and PSS together as predictors of different workplace outcomes. In terms of behaviors, one study found both POS and PSS to be predictive of turnover intentions; as hypothesized, employees reporting lower levels of PSS and POS reported higher levels of turnover intentions (Tuzun \& Kalemci, 2011). In this study, the relationship with turnover intentions was stronger for POS $(r=-.48, p<.001, N=304)$ than PSS $(r=-.35, p<.001, N=304)$, indicating that POS is more likely to reduce turnover intentions than PSS. It is worth noting that the relationship between POS and PSS was moderate $(r=.42, p<.001, N=304)$, indicating some overlap between the two constructs.

POS and PSS have also been related together to work attitudes. One study found both POS and PSS to be negatively related to emotional exhaustion, a dimension of burnout (Campbell et al., 2013). POS was found to be a stronger predictor of burnout 
than PSS, implying that POS might be a more direct way to reduce this outcome in employees.

Regarding work-family conflict (WFC), one study posited that both increased PSS and POS would be related to how people successfully handle work-family conflict (Pan \& Yeh, 2012). This study found that POS $(r=-.47, p<.001, N=375)$ was one of the most important variables for predicting WFC, and that PSS $(r=-.22, p<.001, N=$ 375) was also significant, although not as strong a predictor as POS. POS and PSS had a significant and strong relationship to one another $(r=.57 p<.001, N=375)$, indicating the possibility of redundancies between them in relation to WFC.

Studies have also revealed that higher levels of POS and PSS are linked to increased feelings of employee well-being and job satisfaction (Chen, Powell, \& Greenhaus, 2009; Kreiner, 2006; Lapalme, Tremblay, \& Simard, 2009; Ng \& Sorenson, 2008; Pan \& Yeh, 2012). Given both POS and PSS are defined by whether the organization or supervisor displays concern regarding the employee's well-being, studies have shown that higher levels of POS and PSS increase employees feelings of personal well-being. In relation to job satisfaction, one study found both POS and PSS to be positively related with job satisfaction, indicating that increased POS and PSS are likely to lead to higher feelings of satisfaction with a job ( $\mathrm{Ng} \&$ Sorenson). In this study, POS $(r=.62, p<.001, N=6,864)$ had a slightly stronger relationship to job satisfaction than PSS $(r=.52, p<.001, N=6,864)$, suggesting that organizations that care about the wellbeing of their employees and value their contributions are just as likely to predict job 
satisfaction as when supervisors provide this kind of support. POS and PSS resulted in a fairly strong and significant relationship between the two $(r=.58, p<.001, N=6,864)$.

The research on POS and PSS as both separate and combined predictors of work outcomes has provided much insight into the value of these constructs when managing employees. Overall, POS has been found to be a stronger predictor than PSS of their associated outcomes. Furthermore, POS and PSS generally have a moderate to strong correlation with each other, indicating that there may be redundancy between them in their relationships to other outcomes.

In addition to the outcomes that POS and PSS have been related to in previous research, increasing employees' involvement and positive attitudes towards their work is becoming one of the most desired outcomes in the workplace. One specific construct, work engagement, encompasses this interest. As stated earlier, work engagement has been linked to valued workplace outcomes such as job satisfaction, organizational commitment, intention to quit, organizational citizenship behaviors (OCBs), customer satisfaction, organizational success, and financial return on employees, (Dabke \& Patole, 2014; Saks, 2006; Xanthopoulou, Bakker, Demerouti, \& Schaufeli, 2009).

Understanding how POS and PSS might lead to work engagement is important for organizations that wish to reap the benefits of engaged workers. The next section defines work engagement and describes studies using POS and PSS to predict work engagement.

\section{Work Engagement}

One particular attitude that is considered a major topic of interest in organizations globally is work engagement. The definition of work engagement has been 
conceptualized into a multitude of approaches: the Needs-Satisfying Approach as defined by Kahn (1990), the Satisfaction-Engagement Approach as defined by Harter, Schmidt and Hayes (2002), the Multidimensional Approach (Saks, 2006), and the Burnout-Antithesis Approach, which encompasses two schools of thought from Maslach and Leiter (1997) and Shaufeli, Salanova, Gonzalez-Roma, and Bakker (2002).

Kahn (1990) defined engagement as the "harnessing of organization members' selves to their work roles: in engagement, people employ and express themselves physically, cognitively, emotionally, and mentally during role performances" (p. 7). This definition depicts the attachment of employees to work tasks, and the increased level of involvement when they are engaged in their work.

Referencing satisfaction as a primary factor in defining engagement, Harter, Schmidt and Hayes (2002) stated, "The term employee engagement refers to an individual's involvement and satisfaction with, as well as enthusiasm for work" (p. 269). This definition has been used in larger consulting firms such as Gallup as a means of identifying links between work engagement and business unit outcomes (Harter, Schmidt, \& Hayes, 2002; Shaufeli, 2013).

Conceptualized as multi-dimensional construct, Saks (2006) defined work engagement as "a distinct and unique construct consisting of cognitive, emotional, and behavioral components that are associated with individual role performance" (p. 7). These dimensions describe how work engagement involves how employees think, feel, and react to their work. 
In reference to the Burnout-Antithesis Approach, Maslach and Leiter (1997) viewed engagement on a single continuum; with engagement on one end and burnout on the other (Shaufeli, 2013). This type of approach uses a continuum on the basis of comparison, where a lack of work engagement leads to employees experiencing feelings of burnout in regards to their work.

The second view of the Burnout-Antithesis Approach, which has been most widely used in research, "considers work engagement as a distinct concept that is negatively related to burnout" (Shaufeli, 2013, p. 6). Within this approach, work engagement is defined as "a positive, fulfilling, work related stated of mind that is characterized by vigor, dedication, and absorption" (Shaufeli et al., 2002, p. 6). Vigor involves energy, persistence, and resilience while working. Dedication is a strong level of involvement in one's work, along with feeling "a sense of significance, enthusiasm, inspiration, pride, and challenge" (Shaufeli et al., 2002, p. 6). Finally, absorption involves how concentrated and engrossed an employee is in their work, feeling as though time is passing quickly and they have difficulty detaching themselves from their work (Shaufeli, 2013; Shaufeli et al., 2002). Given the amount of research on Shaufeli's (2013) definition, and that it encompasses multiple dimensions of work engagement that are clearly defined and distinctly measureable, this definition and its coordinating dimensions will henceforth be used to reference to work engagement.

\section{POS and PSS as Antecedents of Work Engagement}

Researchers have used both POS and PSS as predictors of work engagement (Dabke \& Patole, 2014; Masterson, Lewis, Goldman, \& Taylor, 2000; Rhoades \& 
Eisenberger, 2002; Rhoades, Eisenberger, \& Armeli, 2001; Saks, 2006). One study, consisting of 102 employees within a variety of organizations, concluded that those with higher POS and PSS were more likely to become engaged to their job (Saks, 2006). The results of this study yielded positive and significant relationships between both POS and PSS with work engagement. POS $(r=.44, p<.001, N=102)$ had a stronger correlation to work engagement than PSS $(r=.25, p<.001, N=102)$; furthermore, only POS contributed significant unique variance in predicting work engagement (Saks, 2006). These findings indicate that perhaps POS is a stronger contributor than PSS in increasing employee's engagement at work. It is worth noting that POS and PSS had a strong, significant relationship with one another $(r=.61, p<.001, N=102)$.

Another study that used POS and PSS to predict work engagement included 130 employees within the Information Technology and Enabled Services (ITES) sector, averaging 27 years old and consisting of $42.5 \%$ females (Dabke \& Patole, 2014). The results yielded positive and significant correlations between both POS and PSS and work engagement, with PSS $(r=.64, p<.01, \mathrm{~N}=130)$ having a slightly stronger relationship with work engagement than $\operatorname{POS}(r=.51, p<.01, N=130)$. This implies that while increased POS and PSS may lead to predicting higher levels of work engagement, perhaps PSS may somewhat be a more important factor. Within a regression analysis, both POS and PSS contributed to significant amounts of variance in predicting work engagement, with PSS contributing a greater percentage of variance than POS, which again indicates that PSS may play a more important role in predicting work engagement than POS. 
The research involving POS and PSS as predictors of work engagement provides detailed information regarding the extent to which POS and PSS lead to work engagement. These studies have increased knowledge on what companies can expect to receive from their employees as a result of increasing support on the organizational level and managerial level. Additionally, the results regarding POS and PSS in relationship to work engagement are mixed, in that the stronger relationship to work engagement has differed between POS and PSS. These results make it unclear as to which support, POS or PSS, is more predictive of work engagement.

Despite the extensive research involving POS and PSS, the consistent findings that they are correlated to one another draws attention to the possible redundancy between the two constructs. This relationship raises the issue of overlap between POS and PSS, and the question of whether or not they can truly be considered separate constructs, as well as whether the methods of their measurement plays a role in creating this overlap. The importance of distinguishing between POS and PSS is to clarify whether employees differentiate between their feelings of the organization and their supervisor, or if their perceptions of one lead to the other. The next sections summarize the conceptual relationship between POS and PSS, issues regarding their measurement, and the current study's proposal.

\section{The Hypothesized Relationship Between POS and PSS}

The hypothesized relationship between POS and PSS is matter of debate. Some researchers have claimed that they are similar constructs, whereas others indicate that they are separate. Those claiming that POS and PSS are similar constructs state that POS 
is comprised of PSS, and that a higher level of PSS will lead to an increase in POS (Levinson, 1965; Shanock \& Eisenberger, 2006). The premise behind this belief is that a supervisor is a representative of the organization, therefore, when employees have greater PSS, they are also more likely to perceive higher organizational support. This is a feasible view, given that supervisors are an element of the organization and its environment, and that they are partially representative of the organization.

However, others argue that POS and PSS are two separate constructs (Eisenberger et al., 2002; Hutchison, 1997; Kottke \& Sharafinski, 1988). This is based on the belief that employees develop opinions about the organization as a whole, as well as their supervisor, and it has been suggested that despite employees viewing supervisors as representatives of the organization, they are also able to develop individual relationships with supervisors that they separate from their experience with the organization. In this sense, it can be said that although employees may attach the relationships they have with their managers (PSS) to their overall perceptions of the company (POS), they can also distinguish the two relationships without overlapping.

The consistent finding that POS and PSS are correlated to one another adds to the argument that they are not distinct constructs. Given the body of research stating these two constructs as separate, perhaps it is a matter of their measurement that leads to this identified overlap. The next section will review the current measurements of POS and PSS, and the possible concerns involved. 


\section{The Measurement of POS and PSS}

The measurement of POS and PSS has contributed to the confusion of differentiating between the two constructs. The majority of research on POS and PSS has used the Survey for Perceived Organizational Support (SPOS) to measure POS and its modified version, the Survey of Perceived Supervisor support (SPSS) to measure PSS (DeConinck \& Johnson, 2009; Eisenberger et al., 2002; Lapalme et al., 2009; Pazy \& Ganzach, 2006; Shanock \& Eisenberger, 2006). Perhaps this method of measurement does not capture those unique qualities that separate these constructs, and instead, lead to the consistent correlations between them.

The Survey for Perceived Organizational Support (SPOS) consists of 36 items that are typically responded to on a 1-5 or 1-7 Likert-type agreement scale. The SPOS was developed as a measurement of perceived employer commitment, due to the belief that POS is an antecedent of organizational commitment (Eisenberger et al, 1986). This survey uses a social exchange view to explain the relationship between these two types of commitment, and suggests that the perception of commitment from the organization will contribute to the employee's commitment to the organization (Shore \& Tetrick, 1991). The difference between measures of organizational commitment and the SPOS is that a measure of organizational commitment focuses on employees' attitudes towards the organization, whereas the SPOS emphasizes the employees' perceptions of the organization's attitude towards them (Shore \& Tetrick, 1991).

The Survey of Perceived Supervisor support (SPSS) consists of 16 items on a 1-7 Likert agreement scale. The SPSS was adapted from the SPOS to measure PSS by 
replacing the term "organization" with "supervisor." Given that the definitions of POS and PSS are practically identical in nature, their measurements have been adapted to accommodate these similarities. An example of how the items have been adapted from the SPOS to measure PSS includes the original statement, "My organization really cares about my well-being," that was changed to "My supervisor really cares about my wellbeing." The logic behind this adaptation is that the defining factors of POS and PSS are fundamentally the same, with the difference being the source of support (i.e., at the organization or supervisor level).

Measuring PSS by substituting the term "organization" with "supervisor" raises questions as to whether or not the SPOS and SPSS are able to fully differentiate between the two constructs. The consistent findings that POS and PSS are significantly correlated to one another might be a reflection of their measurement, and the inability of the SPOS and SPSS to capture the unique qualities of each construct. Research has been conducted to test the construct validities of the SPOS and SPSS scales that indicate their ability to measure POS and PSS separately (Hutchison, 1997a; Kottke \& Sharafinski, 1998); however, the scarcity of this research and the lack of studies that duplicate these findings are problematic to the proceeding literature that assumes that they are indeed valid.

\section{The Current Study}

To the extent that there has been little research involving the construct validities of the SPOS and SPSS, it is possible that the multiple studies that resulted in high correlations between POS and PSS may be due to the scales' inability to identify unique characteristics that distinguish these relationships. Given that the SPOS and SPSS are 
identical in nature (with the exception of replacing "organization" with "supervisor"), perhaps these scales are not appropriately differentiating between these two constructs. Therefore, the proposed solution in the current study is to measure POS and PSS using two instruments that are completely distinct from each other in their wording of items, in order to clearly differentiate between them and to better identify any unique factors that contribute to their relationships with other variables.

The purpose of this study was to understand the relationships between POS, PSS, and work engagement, as well as aiming to improve the current methods of measurement of both POS and PSS. Specifically, this study tested whether the proposed exploratory measurements would be able to differentiate between POS and PSS and identify unique characteristics that separate these relationships. Additionally, this study tested the amount of variance uniquely accounted for by POS and PSS in predicting work engagement, in order to understand their impact in predicting this outcome. The results sought to add to the current literature by identifying improved methods of measurement for these constructs, as well as provide an understanding of those factors that lead to work engagement. 


\section{Method}

\section{Participants}

The sample consisted of employees at a healthcare company in Southern California. Data were collected in 2015 at the organization using a company-wide engagement survey. All employees 20 years and older who had been with the company for a minimum of 90 days were invited to take the engagement survey. In total, there were 382 respondents across 16 departments, with a response rate of $76.6 \%$. The sample consisted of $56.0 \%$ women and $44.0 \%$ men. About $30 \%$ of the respondents were in the age range of $40-49$, followed by $26.7 \%$ between $30-39,23.3 \%$ between $50-59$ years, $12.8 \%$ between $20-29$ years, and $7 \% 60$ years and older. The majority of participants were not Hispanic or Latino (86.1\%), followed by Hispanic or Latino (9.6\%). Tenure of employees was categorized as follows: less than one year $(19.4 \%), 1-2$ years $(16 \%), 2-5$ years $(23.8 \%), 5-10$ years $(20.2 \%)$, and over 10 years $(20.7 \%)$. Overall, the sample was generally made up of both men and women, aged 30-49 years old, who were not Hispanic or Latino, and had worked at the company for 2-10 years on average (see Table 1). 
Table 1

Demographic Characteristics of Participants $(N=382)$

\begin{tabular}{|c|c|c|c|}
\hline Variables & & Frequency & Percentage \\
\hline \multicolumn{4}{|l|}{ Gender } \\
\hline & Male & 168 & 44.0 \\
\hline & Female & 214 & 56.0 \\
\hline \multicolumn{4}{|l|}{ Ethnicity } \\
\hline & Not Hispanic or Latino & 329 & 86.1 \\
\hline & Hispanic or Latino & 37 & 9.7 \\
\hline & Not Identified & 16 & 4.2 \\
\hline \multicolumn{4}{|l|}{ Age } \\
\hline & $20-29$ & 49 & 12.8 \\
\hline & $30-39$ & 102 & 26.7 \\
\hline & $40-49$ & 114 & 29.8 \\
\hline & $50-59$ & 89 & 23.3 \\
\hline & 60 and over & 28 & 7.3 \\
\hline \multicolumn{4}{|l|}{ Tenure } \\
\hline & Less than 1 year & 74 & 19.4 \\
\hline & $1-2$ & 61 & 16.0 \\
\hline & $2-5$ & 91 & 23.8 \\
\hline & $5-10$ & 77 & 20.2 \\
\hline & Over 10 years & 79 & 20.7 \\
\hline
\end{tabular}

\section{Measures}

Factor analyses. A principal component analysis was conducted on 25 items to assess whether the proposed measures of POS and PSS were successful in identifying the unique characteristics of each scale that would justify them as separate constructs (see Table 2). The principal component analysis extracted a smaller number of factors based on the eigenvalues that were greater than 1 . In order to have large correlations with a smaller number of factors, and to make large loadings larger and small loadings smaller within each factor, rotation made them easier to interpret. The principal component 


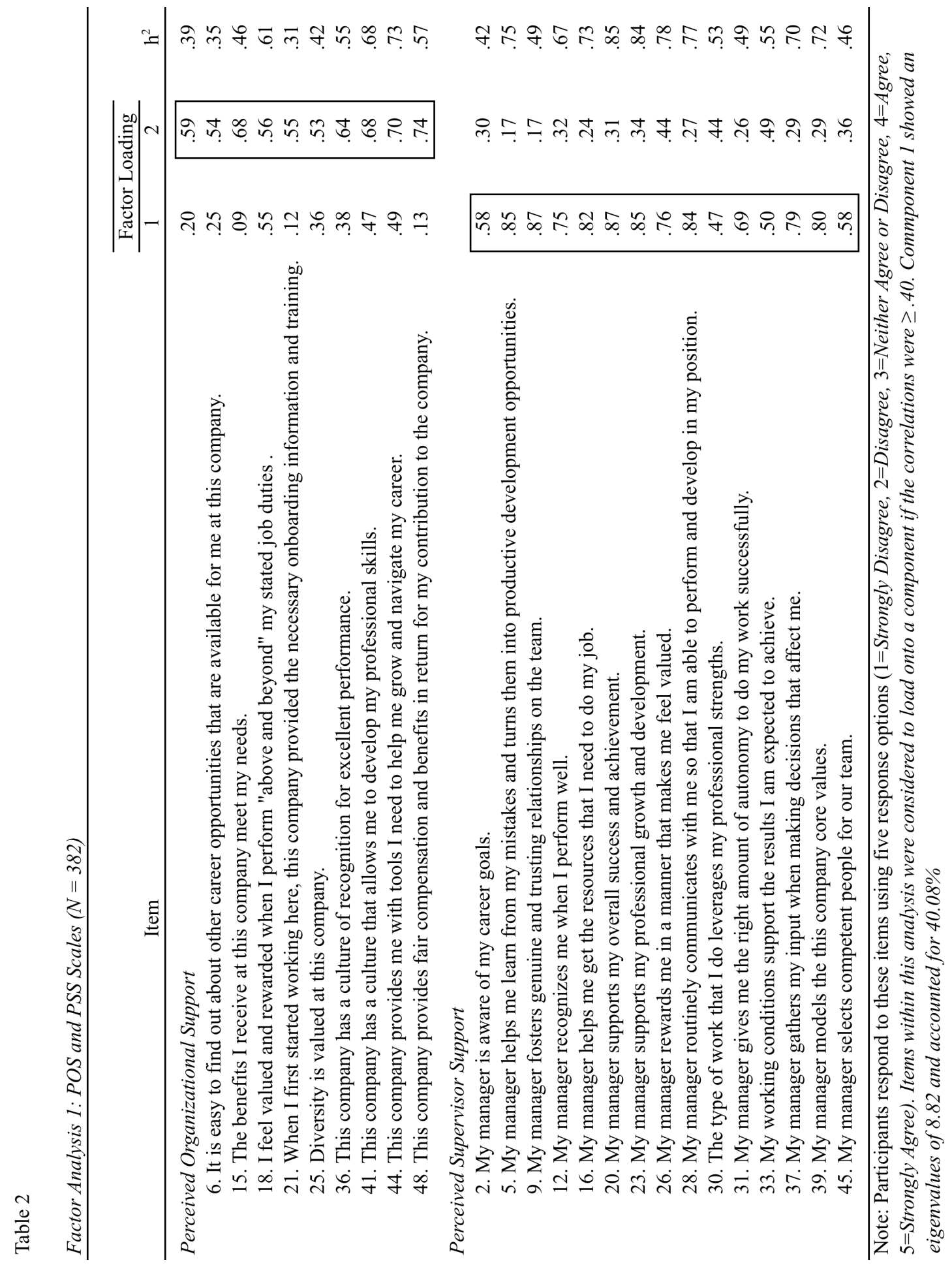


analysis (PCA) was preferred over factor analysis due to it using orthogonal transformation to convert the set of observations into a set of linearly uncorrelated variables into components. A PCA was also more appropriate than a factor analysis given the exploratory nature of the POS and PSS scale development. A Varimax (orthogonal) method of rotation was utilized due to the items in each subscale having been theoretically uncorrelated to one another. All POS and PSS Likert scale items were conducted on data gathered from 382 participants.

Kaiser-Meyer-Olkin and Bartlett tests were run as preliminary analyses to test the assumptions that variables were related to each other. These tests determined whether the variables were sufficiently correlated with each other, in order to justify the factor analysis. Bartlett's test of sphericity was significant, $\chi^{2}(300)=5562.81, p<.001$. An examination of the Kaiser-Meyer-Olkin measure of sampling adequacy suggested that the sample was factorable $(K M O=.96)$. The results of these tests suggest that the factor analysis was justified. The principal component analysis yielded two components with eigenvalues greater than 1, explaining a total of $59.95 \%$ of the variance in the POS and PSS items. The criterion for inclusion on component loadings was for the correlations to be $\geq .40$ between items and components.

Fourteen items loaded onto Component 1, which were generally related to employee perceptions of supervisor support. Component 1 included items with high factor loadings such as "My manager fosters genuine and trusting relationships on the team" (.87), "My manager supports my overall success and achievement" (.87), and "My 
manager supports my professional growth and development" (.85). This component was labeled 'Perceived Supervisor Support.' Component 1 accounted for $52.24 \%$ of the variance within the POS and PSS scales, and was the highest percentage of variance accounted for across the two factors.

Eleven items loaded onto Component 2, which were related to employee perceptions of organizational support. Component 2 included items with high factor loadings such as "This company provides fair compensation and benefits in return for my contribution to the company" (.74), "This company provides me with tools I need to help me grow and navigate my career" (.69), and "This company has a culture that allows me to develop my professional skills" (.68). Component 2 was labeled 'Perceived Organizational Support'. Component 2 accounted for $7.71 \%$ of the variance within the POS and PSS scales.

Item 18 (part of the POS scale), measuring whether employees felt valued and rewarded when performing "above and beyond" their stated duties, loaded onto both Component 1 and 2 equally $(.55, .56$, respectively). It is possible this item loaded onto both components, given that two items in the PSS scale, "My manager rewards me in a manner that makes me feel valued", and My manager recognizes me when I perform well", and were similar in nature. Item 30 (part of the PSS scale), measuring whether the type of work done leverages employees' professional strengths, loaded onto both components somewhat equally $(.47, .44$, respectively). This item may have loaded onto both components due to the similarity with PSS items "My manager supports my overall 
success and achievement", and "My manager supports my professional growth and development”.

Given that items 18,30 , and 33, loaded on both components, a second principal components analysis was conducted in order to further differentiate between the scales. Items 18,30 , and 33 were omitted, for a total of 22 items entered into the analysis to assess whether the revised measure of POS and the proposed measure of PSS were successful in identifying the unique characteristics of each scale that would justify them as separate constructs.

Thirteen items loaded onto Component 1, which were all related to employee perceptions of supervisor support. Component 1 included items with high factor loadings such as "My manager fosters genuine and trusting relationships on the team" (.87), "My manager supports my overall success and achievement" (.87), and "My manager supports my professional growth and development" (.86). This component was labeled 'Perceived Supervisor Support'. Component 1 accounted for $40.08 \%$ of the variance within the PSS and POS scales, and was the higher percentage of variance accounted for across the two factors.

Nine items loaded onto Component 2, which were all related to employee perceptions of organizational support. Component 2 included items with high factor loadings such as "This company provides fair compensation and benefits in return for my contribution to the company" (.74), "This company provides me with the tools I need to help me grow and navigate my career" (.69), and "The benefits I receive at this company 
meet my needs" (.69). This component was labeled 'Perceived Organizational Support'. Component 2 accounted for $21.10 \%$ of the variance within the PSS and POS scales. The results of the second PCA suggest that Component 1 reflects 'Perceived Supervisor Support', as defined in the PSS scale. Component 2 reflected 'Perceived Organizational Support', as defined in the POS scale. Overall, the proposed scales matched the second factor analysis results of two components, which defined both POS and PSS (see Table 3).

Perceived organizational support (POS). POS was defined as a general belief in which employees feel that their organization values their contributions and cares about their well-being (Krishhan \& Mary, 2012; Rhoades and Eisenberger, 2002; Settoon, Bennett, \& Liden, 1996). POS was measured with nine items, such as "My working conditions support the results I am expected to achieve," "This company has a culture that allows me to develop my professional skills," and "When I first started working here, this company provided the necessary onboarding information and training". The response format for the survey items consisted of a 5 -point Likert scale of agreement $(1=$ Strongly Disagree, 5 = Strongly Agree). Employee responses were averaged to create an overall POS score ranging between 1 to 5 . Higher scores indicate that respondents perceived their organization to be more supportive. Cronbach $\alpha$ was .88 , indicating high reliability of the scale.

Perceived supervisor support (PSS). PSS was defined as the extent to which employees believe their supervisors value their contributions, offer assistance, and care 


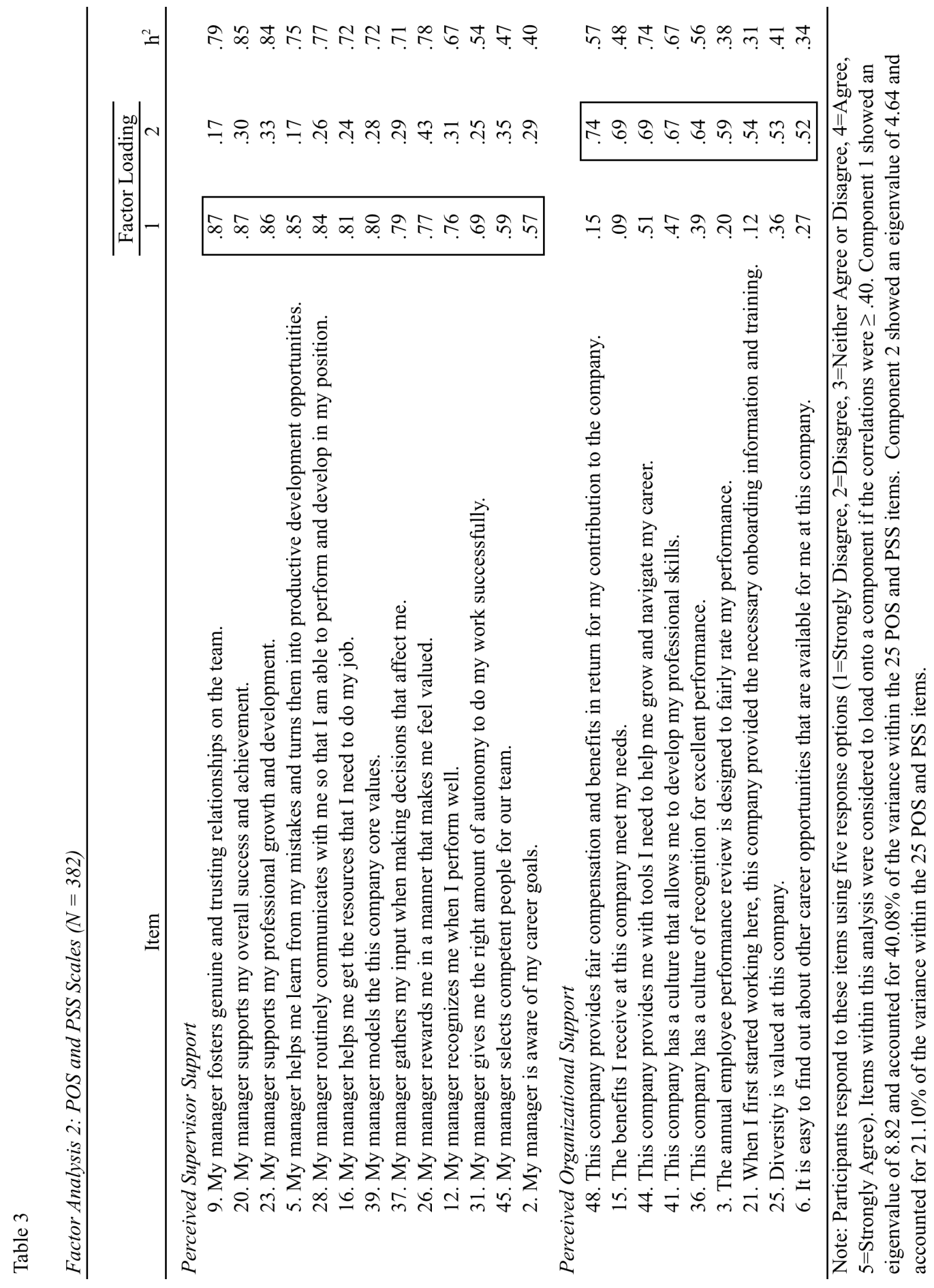


about their well-being (Cole, Bruch, \& Vogel, 2006; Eisenberger et al., 2002; House, 1981; Kossek, Pichler, Bodner, \& Hammer, 2001; Kottke \& Sharafinski, 1988). PSS was measured with 13 items such as "My manager fosters genuine and trusting relationships on the team," "My manager supports my professional growth and development," and "My manager routinely communicates with me so that I am able to perform and develop in my position." The response format for the survey items consisted of a 5-point Likert scale of agreement $(1=$ Strongly Disagree, $5=$ Strongly Agree $)$. Participant responses were totaled and averaged to create an overall perceived supervisor support score ranging from 1 to 5 . Higher scores indicate that participants perceived their supervisors to be more supportive. Cronbach $\alpha$ was .94 , indicating high reliability of the scale.

Work engagement. Work engagement was defined as the employee's intent to stay, willingness to refer the organization to others, and discretionary effort made on behalf of the employee in their work (Ware, 2012). Work engagement consists of the level of vigor, dedication, and absorption involved in one's work (Shaufeli, 2002). Work engagement was measured with nine survey items, such as “On most days, I feel motivated to perform in my position," "I am proud to work for this company," and "I am passionate about the work I do here.” The response format for the survey items consisted of a 5-point Likert scale of agreement (1= Strongly Disagree, 5= Strongly Agree). Participant responses were totaled and averaged to create an overall work engagement score ranging from 1 to 5 . Higher scores indicate that participants are more engaged in their work. Cronbach $\alpha$ was .88 , indicating high reliability of the scale. 
Demographic information. Participants were asked their gender, age, race, and tenure. Gender was measured with the choice of selecting either "man" or "woman." Age was grouped into various ranges, including: 20-29, 30-39, 40-49, 50-59, and 60 and over. Race was measured by identifying as either "Hispanic or Latino," "Not Hispanic or Latino," or "Not Identified." Finally, tenure was broken down into groups dependent on the number of years employed at the organization. These groups included those that had been with the company for "Less than 1 year," "1-2 years," "2-5 years," "5-10 years," and "Over 10 years."

\section{Procedure}

An external vendor was selected to conduct the employee engagement survey on behalf of the organization. All participants received an email inviting them to take the survey, and were provided with a link to the survey website and a unique login username and password. The survey duration was two weeks, and all surveys were completed online at various times either at home, work, or a location of their choice using a computer or cell phone. Upon logging in to the survey, respondents were given a message explaining the purpose and goals of the survey, including using their aggregate responses to identify opportunities to improve the work experience within the company. The message also assured the respondents of the confidentiality of their responses by stating that no one in the company itself would ever see their responses. All survey submissions were collected once the participant pressed the "submit and continue" button. 
After the survey completion date, the vendor's data programmer created a database consisting of the survey responses and demographic information, and all identifying information was removed to ensure confidentiality of the participants' responses and demographic information. With permission of the external vender, the data set was provided to the researcher. 


\section{Results}

\section{Descriptive Statistics}

Descriptive statistics were computed to summarize and describe the data. Table 4 displays the means and standard deviations of the measured variables. Overall, work engagement was above the midpoint of the 1-5 Likert scale of agreement with small variability $(M=4.32, S D=.66)$, indicating that work engagement was relatively high and employees generally felt the work they were doing was stimulating and they wanted to devote themselves to their work, felt their work was meaningful to them, and were fully immersed while doing their work. The POS scale $(M=3.67, S D=.78)$ had a mean above its midpoint and had moderate variability, suggesting that employees generally felt that the organization valued their contributions and cared about their well-being. The PSS scale $(M=3.97, S D=.91)$ also had a mean above its midpoint and had moderate variability, suggesting that employees generally felt that their supervisors valued their contributions and well-being. POS had a lower overall mean than PSS; however, the variability in PSS was greater than POS, suggesting that although employees felt their supervisors were more supportive than the organization, the responses regarding the organization were more consistent than those regarding managers. Overall, employees were engaged in their work, and felt that the company and their supervisors were supportive of them. 
Table 4

\begin{tabular}{lcc}
\multicolumn{3}{c}{ Descriptive Statistics of Variables $(N=382)$} \\
\hline Variable & $M$ & $S D$ \\
\hline Perceived organizational support & 3.67 & .78 \\
Perceived supervisor support & 3.97 & .91 \\
Work engagement & 4.32 & .66 \\
\hline
\end{tabular}

\section{Pearson Correlations}

Pearson correlations were computed to examine the relationships among the three variables. Table 5 presents the correlations among the three variables. The Pearson correlations revealed that all three variables were significantly and positively related to one another. Specifically, POS was positively and significantly related to work engagement, in that higher perceptions of support from their organization was related to an increase in work engagement, $r(380)=.68, p<.001$. PSS was also positively and significantly related to work engagement, in that higher perceptions of support from their supervisors was related to an increase in work engagement, $r(380)=.63, p<.001$. POS was slightly more correlated with work engagement than PSS, which may indicate that POS is more likely to increase engagement than PSS. POS and PSS were also significantly and positively related to one another, suggesting that higher perceptions of organizational support increased perceptions of supervisor support, and vice versa, $r(380)$ $=.67, p<.001$. Overall, these results indicate that the more workers perceived support from the organization and their supervisors, the more they were engaged with their work. 
As employees perceived their organization as supportive, they were also more likely to perceive their supervisors as supportive.

Table 5

Pearson Correlations of Variables $(N=382)$

\begin{tabular}{lccc}
\hline \multicolumn{1}{c}{ Variable } & 1 & 2 & 3 \\
\hline 1. Percevied organizational support & -- & & \\
2. Perceived supervisor support & $.67^{* *}$ & -- & \\
3. Work Engagement & $.68^{* *}$ & $.63^{* *}$ & -- \\
\hline & & & $* * p<.001$
\end{tabular}

\section{Inferential Statistics}

Standard multiple regression analysis. In order to test the research question of whether the proposed measure could identify the unique qualities in POS and PSS to justify them as separate constructs in predicting work engagement, a standard multiple regression analysis was conducted. Table 6 reports the results of the standard multiple regression analysis. Because research has been mixed as to whether POS and PSS are separate constructs, a standard multiple regression analysis was first ran in order to identify whether POS and PSS were able to independently and significantly predict work engagement in no specific order. POS and PSS were entered together in order to examine the amount of variance each accounted for as antecedents of work engagement. 
Table 6

Standard Multiple Regression Analysis: Predicting Work Engagement From POS and PSS

\begin{tabular}{lccc}
\hline \multicolumn{1}{c}{ Variable } & $R^{2}$ & $\beta$ & $t$ \\
\hline & $.51^{* *}$ & & \\
Perceived organizational support & $.46^{* *}$ & 9.52 \\
Perceived supervisor support & $.31^{* *}$ & 6.49 \\
\hline Note: $N=382$. & & $* * p<.001$
\end{tabular}

POS and PSS were significantly related to work engagement, $F(2,379)=197.20$, $p<.001$. POS and PSS combined accounted for $51 \%$ of the variance in predicting work engagement $\left(R^{2}=.51, R_{a d j}^{2}=.51\right)$. POS made a significant unique contribution to work engagement $(\beta=.46, t=9.52, p<.001)$, indicating that as employees perceived their organization to be more supportive, they were also more likely to become engaged in their work. PSS also made a significant unique contribution to work engagement $(\beta=$ $.31, t=6.49, p<.001)$, suggesting that as employees perceived their supervisor to be more supportive, they were more likely to become engaged in their work. Overall, the results of the standard multiple regression analysis support the research question of whether POS and PSS are antecedents of work engagement. It was found that both POS and PSS uniquely predicted work engagement, which implies that employees who perceive they are receiving support from both the organization and their supervisors are more likely to become engaged in their work.

Hierarchical multiple regression analysis. To test the research question of whether POS and PSS are separate constructs, and to see if PSS accounted for a 
significant proportion of the variance above and beyond POS in predicting work engagement, a hierarchical multiple regression analysis was conducted. Because previous research has indicated that POS comprises of PSS, a hierarchical multiple regression analysis was chosen in order to observe the incremental effects of PSS after POS was taken into account, and to measure whether PSS was in fact a separate perception from POS. To control for perceived organizational support, POS was entered in the first step. To measure the incremental effect that perceived supervisor support had above and beyond perceived organizational support, PSS was entered into step 2. Results of the analysis are shown in Table 7.

Table 7

Hierarchical Multiple Regression Analysis: Predicting Work Engagement From POS and PSS

\begin{tabular}{lcccr}
\hline \multicolumn{1}{c}{ Step and predictor variable } & $r$ & $\beta$ & $R^{2}$ & $\Delta R^{2}$ \\
\hline Step 1 Perceived organizational support & $.68^{* *}$ & $.68^{* *}$ & $.46^{* *}$ & \\
Step 2 Perceived supervisor support & $.63^{* *}$ & $.32^{* *}$ & $.51^{* *}$ & $.05^{* *}$ \\
\hline Note: $N=382$. & & & & $* * p<.001$
\end{tabular}

In the first step, POS was entered. Perceived organizational support was significantly related with work engagement, $F(1,380)=317.86, p<.001$. POS accounted for $46 \%$ of the variance $\left(R^{2}=.46, R_{a d j .}^{2}=.45\right)$. POS made a significant and unique contribution to work engagement $(\beta=.68, t=17.83, p<.001)$, indicating that employees who perceived more support from the organization were more likely to be engaged in their work. 
In the second step, PSS was entered. Overall, the combined PSS and POS were found to be significantly related to work engagement, $F(2,379)=197.20, p<.001$. POS and PSS together accounted for $51 \%$ of the variance $\left(R^{2}=.51, R_{a d j .}^{2}=.51\right)$. PSS had a small yet significant incremental effect in predicting work engagement above and beyond $\operatorname{POS}\left(\Delta R^{2}=.05, \Delta F(1,379)=42.14, p<.001\right)$, indicating that higher perceptions of supervisor support was related to an increase of work engagement above and beyond POS.

Overall, the results of the hierarchical MRC showed that perceived supervisor support predicted work engagement above and beyond perceived organizational support. It was found that perceived supervisor support predicted work engagement above and beyond perceived organizational support. Specifically, in step 1, POS had a significant relationship with work engagement, in that higher perceptions of organizational support led to more work engagement. In step 2, PSS had a significant incremental effect above and beyond POS in predicting work engagement. These results suggest that those employees with higher perceptions of organizational support and supervisor support are more likely to be engaged in their work. 


\section{Discussion}

The first goal of this study was to develop measures designed to assess the unique characteristics of POS and PSS in order to differentiate between them as two separate constructs. The second purpose of this study assessed the proposed scales of POS and PSS as antecedents of work engagement. To some extent, the results supported that POS and PSS were separate constructs, and the proposed measures were predictors of work engagement. The sections below summarize the results, propose theoretical and practical implications, discuss strengths and limitations of this study, make suggestions for future research, and draw a conclusion.

\section{Summary of Results}

The first research question was whether proposed measures of POS and PSS would identify unique characteristics that justify them as separate constructs. The results of factor analyses suggest that the proposed measures were able to distinguish between POS and PSS as two different constructs. Two distinct components were created using the proposed POS and PSS scales, where after redundant items were removed, items of each scale successfully loaded onto their own components. However, POS and PSS had a moderately high correlation, which would indicate that although employees can differentiate between POS and PSS, they still see overlap between them. These results suggest that employees do distinguish between perceptions of organizational and supervisor support; however, POS is likely to include PSS, in that perceptions of organizational support is also like to involve how employees perceive support from their supervisors. Therefore, although the proposed measures successfully identified unique 
characteristics and separate these constructs, analyses revealed that perceptions of supervisor support might be included in employees' perceptions of organizational support.

The second research question was whether the proposed measures could be used to establish that POS and PSS are predictors of work engagement. A standard MRC analysis resulted in POS and PSS together contributing to a significant percentage of the variance in work engagement. However, as POS contributed to the vast majority of the variance in predicting work engagement, and PSS made only a slight yet significant contribution, it may be that perceptions of supervisor support are primarily included in perceptions of organizational support. Additionally, a hierarchical MRC analysis resulted in POS accounting for most of the variance in predicting work engagement, with PSS only adding a slight percent increase above and beyond POS. This indicates that although PSS does contribute to a significant amount of the variance in work engagement above and beyond POS, perceptions of organizational support make up most of the variance in work engagement between POS and PSS. Therefore, POS accounts for the majority of the predictability in work engagement, while PSS only contributes slightly to predicting work engagement.

\section{Theoretical Implications}

This study provides an initial understanding of how the proposed measures identify unique characteristics that distinguish between POS and PSS, and confirms the results of previous research that imply that they are predictors of work engagement. These results are mostly consistent with the previous research, where POS and PSS were 
strongly correlated with one another, and POS had stronger relationships to outcome variables than PSS. Similar to a study by Saks (2006), POS had a stronger relationship with work engagement than PSS and accounted for the most unique variance in predicting work engagement. However, the findings of the current study contradict those of Dabke and Patole (2014), where PSS had a slightly stronger relationship with work engagement than POS.

Given that in a large majority of previous research, POS resulted in the strongest relationships compared to other predictors with workplace outcomes, perhaps the results of the study by Dabke and Patole (2014) were due to confounding factors involving the types of participants, the size of the organization, or the company culture, which could have influenced the importance of supervisor support in the workplace when predicting work engagement. For example, the participants in this study were working in the Information Technology and Enabled Services (ITES) sector, which is particularly isolated from face-to-face interaction (Dabke \& Patole). Perhaps in this situation, support from the supervisors was more important than support from the organization, due to supervisors being their main source of communication and contact.

\section{Practical Implications}

The implications that can be drawn from this study are that organizations trying to foster work engagement are more likely to be successful if they provide employees with organization-wide support. Consistent with social exchange theory, organizations that are perceived to show concern and care towards their employees create feelings of obligation for the employees to reciprocate through outcomes like work engagement 
(Saks, 2006). Therefore, organizations striving to improve work engagement should focus on employee perceptions of support from the organization (Saks, 2006). Incorporating support for their employees throughout the organization's policies, norms, and culture are likely to provide their employees with a sense that the organization values them and cares about their well-being. For example, ensuring that employees receive the proper resources in training, are protected by workplace policies and procedures, are treated fairly, and acknowledging those that make valuable contributions, will help promote engagement.

Additionally, organizations can also provide support through its agents, such as employees' supervisors. Given the results of this study, organizations that encourage their supervisors to provide employees with resources, emotional support, and benefits are more likely to have employees reciprocate with work engagement. Supervisors can do this by rewarding employee contributions, offering assistance, finding ways to show that they care about employees' well-being, and keeping interactions between employees positive. It is important that supervisors explore the interests and needs of their employees in order to create a sense of obligation that is reciprocated by greater levels of engagement (Saks, 2006).

\section{Strengths and Limitations of The Current Study}

Strengths. One strength of this study is that the proposed measures of POS and PSS were able to identify characteristics unique to each construct. Given that factor analyses resulted in two distinct factors, and the revised analysis (in which highly correlated items were removed due to their redundancies) resulted in the POS and PSS 
items loading onto separate factors, it can be concluded that the proposed measures were successful in distinguishing between POS and PSS. Items that were removed from the scales were found to have been very similar to one another, further supporting the argument that in order to measure POS and PSS separately, it is important to do so with scales that are not redundant. In other words, given that previous measurements of POS and PSS utilize identical scales with the exception of replacing the term "organization" with "supervisor," the results of this study indicate that in order to distinguish between these constructs, it is necessary to incorporate measurements (such as those proposed in this study) that uniquely measure the characteristics of each construct.

Another strength of this study is that the sample size was large, with variations in age, gender, and tenure, which indicate that the results are likely to be representative of a larger population. Given the sample size of 382 participants, and fairly equal distributions across demographics, the current study is not likely to have confounding factors due to demographic information that may have skewed the data. This increases the possibility that inferences drawn from these results can be successfully applied within various types of work environments. For example, due to the variations of tenure in this sample, organizations can infer that regardless of the length of employment, POS and PSS are likely to help promote work engagement across all employees.

Limitations. One limitation of this study is that although the demographic information was generally distributed across different groups, the industry in which the sample was collected was fairly narrow. Given that the data collected were from a healthcare company, the results may have been impacted. For example, employees of 
healthcare companies might be more likely focused on the mission, vision, and values of the organization, which could have influenced the findings that POS was a stronger contributor to work engagement than PSS. It may be that industries whose products or services evoke more passion and emotion in employees are more likely to emphasize the importance of support from the organization, which might result in POS making a greater impact on work engagement than PSS. Due to the inability to collect data across several industries, the application of these results may be more specific to organizations in which POS is likely to be an important factor.

Another limitation of this study is that the data collected on ethnicity were not very diverse. Information was gathered on the basis of employees having been of Hispanic descent, not of Hispanic descent, or not identified. This limits the ability to infer that the results of this study can be used in diverse settings, given that participants were not further differentiated into specific ethnic groups.

\section{Future Research}

Due to the proposed measures of POS and PSS being exploratory in nature, the implications of this study are limited. In order to contribute to both the practical and theoretical implications of these findings, additional research is necessary. The following suggestions seek to improve the present study.

First, because the research that includes POS and PSS as separate constructs in predicting work engagement is limited, it is suggested that subsequent research gain a more thorough understanding of this topic. Specifically, research should be aimed at measuring POS and PSS distinctly using the proposed measures to identify and confirm 
which type of support should be the focus when trying to encourage work engagement. Because this research is limited, it is also suggested that future research include variations in ethnic groups and industry type to build on the theoretical and practical implications that can be drawn by the current study. Further knowledge on how ethnic groups and industries react to POS and PSS differently in relation to work engagement will allow a more thorough understanding of which of the two makes a stronger contribution to work engagement, and whether ethnicity or industry type affects the application of these results.

Second, given that the proposed measures were able to differentiate between POS and PSS, but PSS was unable to contribute much to predicting work engagement once POS was accounted for, further research is necessary to understand whether POS and PSS are distinct constructs in predicting workplace outcomes. The results of this study may imply that while employees distinguish between POS and PSS, perceptions of organizational support is likely to incorporate how employees perceive their supervisors to be supportive as well. However, the type of work outcomes that POS and PSS are associated with may affect the ability of employees to differentiate between these constructs.

Perhaps the fact that work engagement is broader in nature, it could be that the similarly broad nature of POS is better able to capture factors that contribute to employees becoming engaged in their work. Therefore, although the results of this study may imply that POS includes PSS, it may be that their distinctiveness is dependent on the type of work outcomes being measured. Work outcomes that are narrower or specific in 
nature, such as how employees treat their co-workers, employee morale, and perceptions of fairness regarding performance evaluations, may result in PSS contributing more to the variance than POS. In these cases, it may not be that POS and PSS are not distinct; rather, the type of outcome affects the degree to which employees distinguish between their perceptions of the organization and their supervisor, and how important they feel each one is in regards to various work outcomes.

\section{Conclusion}

Many organizations today are seeking to incorporate methods that will help them retain their talent and gain the advantage in a competitive and constantly changing environment. Studies measuring how various types of support can be beneficial increase the ability of organizations to understand how to leverage this information in fostering positive workplace outcomes. Given that perceptions of organizational and supervisor support have been shown to lead to positive workplace outcomes, further exploration of how POS and PSS distinctly contribute to predicting these outcomes can increase understanding of the relative impact the organization and its supervisors have on employee behaviors and attitudes. Specifically, with the recent interest in the benefits of work engagement, research directed toward understanding how POS and PSS affect employee engagement at work will allow companies to incorporate and encourage factors that are likely to result in more engaged employees. The results of this study can be used towards contributing to the theoretical knowledge of POS and PSS, and help organizations gain a better understanding of how to encourage work engagement by providing employees organizational and supervisor support. 


\section{References}

Babin, B. J., \& Boles, J. S. (1996). The effects of perceived co-worker involvement and supervisor support on service provider role stress, performance and job satisfaction. Journal of Retailing, 72, 57-75.

Baran, B. E., Shanock, L. R., \& Miller, L. R. (2012). Advancing organizational support theory into the twenty-first century world of work. Journal of Business and Psychology, 27, 123-147.

Blau, P. M. (1964). Exchange and power in social life. New York: Wiley.

Campbell, N. S., Perry, S. J., Maertz, C. P., Allen, D. G., \& Griffeth, R. W. (2013). All you need is resources: The effects of justice and support on burnout and turnover. Human Relations, 66, 759-782.

Chen, Z., Eisenberger, R., Johnson, K. M., Sucharski, I. L., \& Aselage, J. (2009). Perceived organizational support and extra-role performance: which leads to which?. The Journal of Social Psychology, 149, 119-124.

Chen, Z., Powell, G. N., \& Greenhaus, J. H. (2009). Work-to-family conflict, positive spillover, and boundary management: A person-environment fit approach. Journal of Vocational Behavior, 74, 82-93.

Cole, M. S., Bruch, H., \& Vogel, B. (2006). Emotion as mediators of the relations between perceived supervisor support and psychological hardiness on employee cynicism. Journal of Organizational Behavior, 27, 463-484.

Crabtree, S. (2005). Engagement keeps the doctor away. Gallup Management Journal, $13,1-4$.

Dabke, D., \& Patole, S. (2014). Predicting employee engagement: Role of perceived organizational support and supervisor support. Tactful Management Research Journal, 3, 1-8.

DeConinck, J. B., \& Johnson, J. T. (2009). The effects of perceived supervisor support, perceived organizational support, and organizational justice on turnover among salespeople. Journal of Personal Selling \& Sales Management, 29, 333-350.

Eder, P., \& Eisenberger, R. (2008). Perceived organizational support: Reducing the negative influence of coworker withdrawal behavior. Journal of Management, 34, $55-68$. 
Eisenberger, R., Armeli, S., Rexwinkel, B., Lynch, P. D., \& Rhoades, L. (2001).

Reciprocation of perceived organizational support. Journal of Applied

Psychology, 86, 42-51.

Eisenberger, R., Fasolo, P., \& Davis-LaMastro, V. (1990). Perceived organizational support and employee diligence, commitment, and innovation. Journal of Applied Psychology, 75, 51-59.

Eisenberger, R., Stinglhamber, F., Vandenberghe, C., Sucharski, I. L., \& Rhoades, L. (2002). Perceived supervisor support: Contributions to perceived organizational support and employee retention. Journal of Applied Psychology, 87, 565-573.

George, J. M., \& Brief, A. P. (1992). Feeling good-doing good: A conceptual analysis of the mood at work-organizational spontaneity relationship. Psychological Bulletin, $112,310-329$.

Harter, J. K., Schmidt, F. L., \& Hayes, T. L. (2002). Business-unit-level relationship between employee satisfaction, employee engagement, and business outcomes: A meta-analysis. Journal of Applied Psychology, 87, 268-279.

House, J. S. (1981). Work stress and social support. Reading, MA: Addison-Wesley; 1981.

Hutchison, S. (1997). A path model of perceived organizational support. Journal of Social Behavior and Personality, 12, 159-174.

Hutchison, S. (1997). Perceived organizational support: Further evidence of construct validity. Educational and Psychological Measurement, 57, 1025-1034.

Kahn, W. A. (1990). Psychological conditions of personal engagement and disengagement at work. Academy of Management Journal, 33, 692-724.

Kossek, E. E., Pichler, S., Bodner, T., \& Hammer, L. B. (2011). Workplace social support and work-family conflict: A meta-analysis clarifying the influence of general and work-family-specific supervisor and organizational support. Personnel Psychology, 64, 289-313.

Kottke, J. L., \& Sharafinski, C. E. (1988). Measuring perceived supervisory and organizational support. Educational and Psychological Measurement, 48, 10751079.

Kreiner, G. E. (2006). Consequences of work-home segmentation or integration: A person-environment fit perspective. Journal of Organizational Behavior, 27, 485507. 
Krishnan, J., \& Mary, V. S. (2012). Perceived organisational support-an overview on its antecedents and consequences. International Journal of Multidisciplinary Research, 2, 2-3.

LaMastro, V. (2000). Commitment and perceived organizational support. National Forum of applied educational research journal 13, 1-13.

Lapalme, M. È., Tremblay, M., \& Simard, G. (2009). The relationship between career plateauing, employee commitment and psychological distress: The role of organizational and supervisor support. The International Journal of Human Resource Management, 20, 1132-1145.

Levinson, H. (1965). Reciprocation: The relationship between man and organization. Administrative Science Quarterly, 9, 370-390.

C. Maslach, S.E. Jackson, and M.P. Leiter (1996). The Maslach Burnout Inventory (3rd ed.). Palo Alto, CA: Consulting Psychologists Press.

Masterson, S. S., Lewis, K., Goldman, B. M., \& Taylor, M. S. (2000). Integrating justice and social exchange: The differing effects of fair procedures and treatment on work relationships. Academy of Management Journal, 43, 738-748.

Meyer, J. P., \& Allen, N. J. (1991). A three-component conceptualization of organizational commitment. Human Resource Management Review, 1, 61-89.

Ng, T. W., \& Sorensen, K. L. (2008). Toward a further understanding of the relationships between perceptions of support and work attitudes: A meta-analysis. Group \& Organization Management, 33, 243-268.

Pan, S., \& Yeh, Y. (2012). Impact of value congruence on work-family conflicts: The mediating role of work-related support. Journal of Social Psychology, 152, 270287.

Pazy, A., Ganzach, Y., \& Davidov, Y. (2006). Decision-making training for occupational choice and early turnover: A field experiment. Career Development International, $11,80-91$.

Ram, P., \& Prabhakar, G. V. (2011). The role of employee engagement in work-related outcomes. Interdisciplinary Journal of Research in Business, 1, 47-61. 
Randall, M. L., Cropanzano, R., Bormann, C. A., \& Birjulin, A. (1999). Organizational politics and organizational support as predictors of work attitudes, job performance, and organizational citizenship. Journal of Organizational Behavior, 20, 159-174.

Rhoades, L., \& Eisenberger, R. (2002). Perceived organizational support: A review of the literature. Journal of Applied Psychology, 87, 698.-714

Rhoades, L., Eisenberger, R., \& Armeli, S. (2001). Affective commitment to the organization: The contribution of perceived organizational support. Journal of Applied Psychology, 86, 825-836.

Saks, A. M. (2006). Antecedents and consequences of employee engagement. Journal of Managerial Psychology, 21, 600-619.

Schaufeli, W. B. (2013). What is engagement? In C. Truss, K. Alfes, R. Delbridge, A. Shantz, \& E. Soane (Eds.), Employee Engagement in Theory and Practice. London: Routledge.

Schaufeli, W. B., Salanova, M., Gonzalez-Roma, V., \& Bakker, A.B. (2002). The measurement of engagement and burnout and: A confirmative analytic approach. Journal of Happiness Studies, 3, 71-92.

Settoon, R. P., Bennett, N., \& Liden, R. C. (1996). Social exchange in organizations: Perceived organizational support, leader-member exchange, and employee reciprocity. Journal of Applied Psychology, 81, 219-227.

Shanock, L. R., \& Eisenberger, R. (2006). When supervisors feel supported: Relationships with subordinates' perceived supervisor support, perceived organizational support, and performance. Journal of Applied Psychology, 91, 689695.

Shore, L. M., \& Tetrick, L. E. (1991). A construct validity study of the Survey of Perceived Organizational Support. Journal of Applied Psychology, 76, 637-643.

Tuzun, I. K., \& Devrani, T. K. (2011). The impact of perceived employee identification on the relationship between customer company-identification and customer citizenship behaviour: Practice from Turkish hotels. African Journal of Business Management, 5, 1781-1786.

Ware, B. L. (2012). Integral Talent Systems Employee Engagement Survey Manager Tool Kit (Eds.). 
Xanthopoulou, D., Bakker, A. B., Demerouti, E., \& Schaufeli, W. B. (2009). Work engagement and financial returns: A diary study on the role of job and personal resources. Journal of Occupational and Organizational Psychology, 82, 183-200. 